\title{
WILL TECHNICAL CONTROL IN LOGGING OPEN THE DOOR TO BETTER SILVICULTURAL MANAGEMENT?
}

\author{
By L. A. NrX \\ Bathurst Power and Paper Co.
}

INTRODUCTION

CORESTRY, if it means anything, means sylviculture. No Forester is

$F$ living up to the ethics of his profession unless he makes an honest attempt

to keep the forest under his jurisdiction, growing repeated crops of merchantable timber.

There have been several almost insurmountable obstacles in the way, to prevent the private forester of even roughly attaining the principle goal of his profession. These hurdles are too well known and have been discussed so often that it will be unnecessary to mention them again in this paper. Private foresters, who have been sylvicultural idealists, have seen many of their plans come to nothing either because of careless or planless logging. It was probably one of the reasons which was instrumental in forcing many foresters into logging. Private foresters, when employed in forestry departments have been faced with the fact, that their jobs have been born and nourished during boom times, while industry is paying dividends, and, that the passing of dividends means sure demise to their jobs. Logging has meant surer continuity of employment and larger pay. Foresters, whether idealist or practical, could not be expected to pass up this opportunity and perhaps the chances of attaining their goal are as great or even greater, as loggers, than as foresters.

What have foresters, as loggers, done toward the fulfilment of their professional ideals?

The forester logger has introduced technical control into logging. This achievement can properly be claimed by the private forester. Lauderburn tried to introduce sylviculture into logging when he was with the Pejebscot Paper Company. He tied up sylviculture with logging by putting foresters into logging jobs with the idea that they would enable the management to have better control of any attempted forestry practice, and that the foresters would change the logging personnel viewpoint in regard to forestry. Bryce worked along similar lines when he was with the Eastern Manufacturing Co.; and Gilmour must have had some such idea in Newfoundland, when he was with the Anglo-Development Company. These men and others have undoubtedly been the originators of the idea, that if private foresters expected to practice any forestry worthy of the name, forestry must control logging or be very intimately interrelated. 
How or can technical control in logging contribute anything to sylvicultural management?

It goes without saying that logging costs are scrutinized very closely at the present time and that every unnecessary item of expense is cut out. It is also axiomatic that no forester who is handling logging is going to put in any unnecessary expense into his cost schedules that will jeopardize the financial or competitive position of his company but, on the other hand, it is fast coming home to close observers that it is not good business to undermine the future of a company's forest resources in order to save the present.

If there is any possibility of any sylvicultural management by present logging methods, technical control should show the way. Technical control, as far as the forest is concerned, is four fold in scope, as follows:

1. Fact finding surveys and investigations.

2. Systematic planning leading to periodic and yearly schedules and budgets.

3. Field control of operations.

4. Check up survey of operations as a guide to future action.

\section{FACT FINDING SURVEYS AND INVESTIGATIONS.}

Fact finding surveys have fallen into two catagories, namely, stock taking or inventory surveys and cut location.

The inventory surveys have been largely completed and there is a fairly comprehensive picture of a large part of the timberlands of Eastern Canada held by private companies. This data has probably been used mostly for accounting and the planning of the organization. They have been used to show the assets of the company and to lay our a broad scheme of logging. If the knowledge of these surveys were properly analysed, it would be possible to at least map out a broad sylvicultural management plan co-ordinated and harmonized with the broad cutting plan. It is not likely that these inventory surveys have provided all the information that would be needed for a proper sylvicultural management plan, but these shortcomings have or are in the process of being made up by the investigations that are under way by the Dominion and Provincial Forest Services. It is hardly conceivable that any forester could give lack of information as a reason for not attempting some sylvicultural management.

If this were a fact, the second set of surveys, known as cut location, could be made to give any information desired without any appreciable increase in cost. These cut location surveys are usually fairly intensive. They give detailed information regarding the forest topography and any other features that would affect the cost of logging. These surveys are made just previous to logging and are made for the purpose of locating the operation to suit the mill requirements, both as to kind of timber and as a control of costs. These 
surveys give a detailed, accurate picture of the forest area to be logged, and if sylviculture is going to be fitted into any plan, it should and could be put in here.

The forester logger, after these surveys are completed, has the facts that he needs as far as the forest is concerned for future action and is ready for the next step, which is systematic planning.

\section{SYSTEMATIC PLANNING LEADING TO PERIODIC AND YEARLY}

SCHEDULES AND BUDGETS.

Systematic planning is briefly assembling all the facts and tying them up with the cost of delivering a cord or thousand feet of timber to the mill. This means the development of a plan or schedule which takes into consideration each step and its cost, entailed in the job of delivering a definite quantity of wood from various locations in the forest to the mill. It is at this stage of the planning that sylviculture will meet the acid test. It is here that various methods of cutting can be put down in dollars and cents and it will be perfectly apparent whether sylviculture is to be or not to be. Because of the fact that there is to-day almost universally, carefully drawn up periodic and long term plans for logging operations, it occurred to the writer that some sylviculture ought to be considered in these plans. Logging is worked out to-day in such a manner that sylviculture can enter. It was, when there were no surveys and no plans except what some woods boss carried in his head, utterly impossible to do anything about sylviculture. That is not true to-day.

It would be presumptuous for the writer to suggest how any operator is going to put sylviculture into his planning, but if an honest effort were made, a great deal more sylviculture could be worked into the plan without increase of cost of logs to the mill than is or has been the probable case in the past. It is next to useless to expect any plan or schedule to work without intelligent control in the field, a necessary corollary to systematic planning.

FIELD CONTROL OF OPERATIONS.

It is perfectly obvious that if there is planning, there must be, in order to get the maximum benefit out of the plan, intelligent control and execution of the plan. It must also be evident that if any sylviculture is attempted in these cutting plans that a forester must be in control in the field. In logging, a unit of operation may be considered as a jobber or a company camp because this camp or jobber may be cutting one unit or camp cutting area in a compartment of the forest. There are three men in every camp, who play a dominant role in executing the cutting plan, namely: the foreman or jobber, scaler and camp clerk and in some instances a fourth, namely: the inspector of cutting. Everything depends on these men, they are the key men. No plan is worth the paper it is written on unless these men understand it and 
give it their support. The "alibi" is the careless woods man's answer to all plans which go astray and the woods manager has a mighty hard time disproving this alibi.

It seems to the writer that it will be mighty near impossible to expect any sylvicultural management worthy of the name by means of the jobber system of cutting. The writer does not in any way wish to introduce a controversy of Company camp versus the jobber method of logging. Both methods of cutting have their place in an operation, but it would be a grave mistake to put a jobber into a unit where some particular cutting plan had been worked out in order to accomplish some definite sylvicultural object. For some time to come, it will not be possible to accomplish anything sylviculturally in the way of cutting, except by company camps. The greatest objection to company camps has been in the past, a question of the control of camp overhead expense. Such items of expense as liability and compensation insurance, equipment, horses, camp building, road expense and maintenance all have to be provided for, whether it is done by paying a jobber a lump sum to assume all these costs or figure them out item by item for the company camp. It will not be possible very long to get jobbers to take jobs if any of these items are left out; because they are present in every job, and cannot be avoided. If any woods manager thinks he is driving a sharp bargain by leaving out any of these items, he will soon find out that he has a bankrupt jobber on his hands. As regards to the reputed increased camp personnel in company camps, it is the writer's experience that the control of this item of overhead expense, is entirely a matter of picking the right foreman and clerk, and giving them the proper training for the job.

Scaling, clerking, and camp foreman positions offer a chance to the ambitious young forester to get into logging. The continuity of employment, salary and chances of promotion are greater almost in every instance than in straight forestry positions. This fact is probably more true to-day than ever and will likely be much more so in the future.

Before any man, whether forestry trained or not, should be given the chance to take charge of managing a company camp, cutting either logs or pulpwood, he should be put through a course of training which in the writer's opinion would be somewhat as follows:

1. Knowledge of surveying and cruising timber and other types of forestry work, and ability to read and understand forest plans as made for cut location and control.

2. Thorough knowledge of measuring wood, logs and other forest products.

3. Good grounding in accounting so that he will be able to do camp clerking and will be able to analyse camp costs. 
4. Knowledge of all types and kinds of logging machinery and tools and their use.

5. Be able to plan and execute all types of woods construction jobs such as: camps, roads, telephone lines, dams etc.

6. Ability to understand and handle woods labor.

This training will take anywhere from 2 to 5 years, depending on the individual, and at the end of that time a man should be able to direct the cutting as planned, whether it is clear cutting, selection, or what not, and understand the reason for doing it. These men, with the proper training, will hand on their viewpoint in regard to forest management to the man with the axe, so that in time the lumberjack will become a skilled worker instead of just a worker. The old order will change as the viewpoint changes. The time will pass when the greatest qualification a lumberjack can have is a weak mind and a strong back. There will probably never be a time when strong, rugged, physical strength will not be required in woods work, but if sylviculture is ever going to mean anything more than a lip service among private foresters, it will have to be taught, at least elementarily, to the thousands of woods workers of Eastern Canada. Even in our logging practice of today, where there is no definite sylvicultural plan of cutting, any observer can see many practices in the ordinary routine of a woods worker's daily activity, that is harmful to the proper regrowth of the area cut over. This is not due to any maliciousness on the part of the workman, but to habit and ignorance. There is no better way of educating the workman than to have properly educated foremen, clerks and scalers, directing the work in the woods. If these men have the respect of the workmen under them, they can change the habits and mental viewpoints of the woods worker very quickly.

\section{CHECK UP SURVEY AS A GUIDE TO FUTURE ACTION.}

There is very little use having a cutting plan unless a check is made after the plan has been executed in order to find out if the plan has been followed and if there were any errors in the planning, so that any differences between the results and the original plan can be recorded and used for a guide to greater accuracy in future planning.

These check up surveys have many uses. If a sylvicultural method of cutting were used, the surveys might be made in such a manner that they could give information which would serve as a sort of rough sample plot. If examined periodically, it would be possible to note what the results of certain methods of cutting were, and if changes in the cutting method were needed in certain types, these changes could be made in the future cutting plans.

The writer uses a very inexpensive method of checking up the cutting of an area as the job is in progress. He prepares a large scale map of the camp 
area being cut. The scale of the map is 5 chains to the inch. This map is kept in the camp and accompanies the cutting plan. All the roads are kept mapped and plotted on this plan. One man with a hand compass and pacing can map all the roads of a 6000 cord camp in about 6 days. While he is mapping the roads which are all numbered, he makes note of the number of piles of wood or skidways of logs there are on each road, any infractions of government cutting regulations, unnecessary destruction of reproduction, patches of timber not cut, etc. All this information is plotted on the large scale map and becomes part of the permanent record of just what happened to any particular area when it was cut over. This work is done as the camp's cut progresses. By this means the foreman is kept advised in regard to his progress in relation to the plan. Whenever he is not following the original cutting plan and if it is at all possible for him to do so, he corrects the error. This type of survey is usually all that is needed as a check. The plan and a brief report are filed as a record for future reference and guidance. It is the writer's opinion that the best time to check a cutting operation is periodically, while the camp is in progress, because the foreman can have the benefit of the criticism. If the information is plotted on the map in the camp as a record, any difference of opinion about any matter can be located easily on the ground and the dispute settled in the field and on the spot, where all differences of opinion should be settled, not six months later in town in the manager's office. In the case of a pulpwood operation, where there often are as many as 300 to 500 branch roads, going off from perhaps 5 or 6 main roads, these large scale maps are of great value to the foreman in planning and directing his hauling and practically eliminates all chance of any road being overlooked. It also helps the foreman to visualize and compare different methods of laying out a cutting plan to suit different topographical features, since no two areas are exactly the same. The proper lay. ing out of cutting has a large bearing on the costs of getting wood off from a given area, and a foreman cannot have too much knowledge and judgment in this important field of his job.

\section{CONCLUSION}

Forestry is seemly on the threshold of a new era. The foundation is well laid and the information largely at hand for the next step ahead. Technical control in logging can furnish the vehicle for sylviculture, if the viewpoint in connection with handling forest resources can be changed. Much better sylviculture can be practiced without additional expense by educating the woods workers, both the managing personnel and the lumberjack. If the forester-logger in control has the will, it will only require a little ingenuity to practice much better sylviculture than anyone had any idea that it was possible to do. The writer predicts that out of this depression will come new 
ideals, but the forester's ideal of conservation of natural resources by proper use cannot be other than strengthened and revitalized by the trying experiences we have been passing through for over three years. The ideal was always sound and it is stronger now than ever and more impregnable than the rock of Gibraltar.

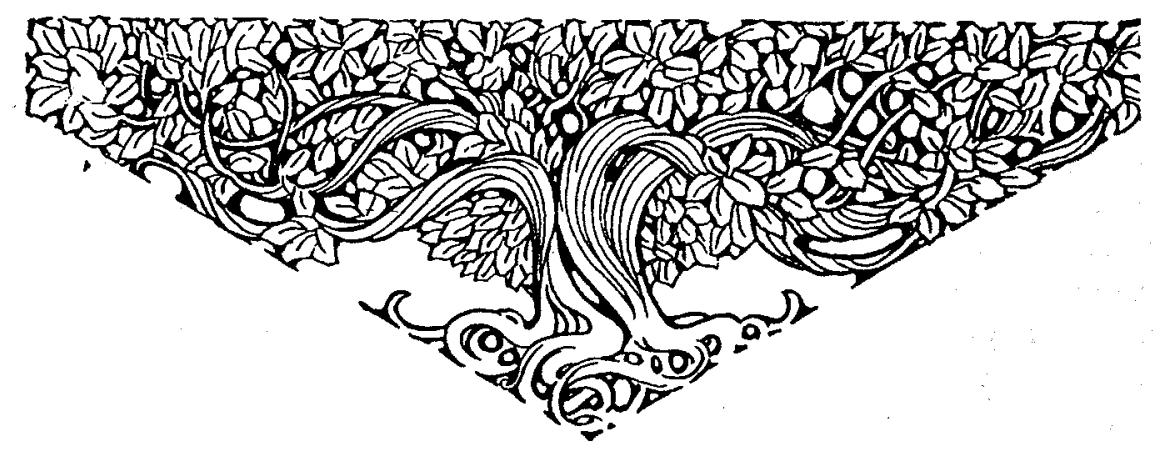

